\title{
Interpretação Analítico-Comportamental do Autocontrole Emocional
}

\author{
Jussara Rocha Batista* \& Emmanuel Zagury Tourinho** \\ Universidade Federal do Pará, Belém, Brasil
}

\begin{abstract}
RESUMO
Algumas abordagens psicológicas diferenciam autocontrole comportamental e autocontrole emocional, este último abordado com a referência a eventos controlados no interior do indivíduo. No presente artigo, discutem-se algumas direções para a interpretação analítico-comportamental do que em outros contextos é referido como autocontrole emocional. Para a Análise do Comportamento, no autocontrole emocional tem-se não um processo diferente do autocontrole comportamental, mas componentes adicionais nos fenômenos investigados, que requerem um tratamento adequado. $\mathrm{O}$ artigo destaca alguns determinantes do padrão de comportamento definido como autocontrole emocional: o contexto social de produção e ocorrência do autocontrole, os conflitos entre consequências para o indivíduo e para o grupo e o grau de participação do aparelho motor na emissão de respostas emocionais.
\end{abstract}

Palavras-chave: autocontrole emocional; respostas emocionais; mundo interno; análise do comportamento.

\section{ABSTRACT \\ The behavior-analytic approach to emotional self-control}

Some psychological approaches distinguish behavioral self-control from emotional self-control, the latter being approached with the reference to inside events controlled by the individual himself. This paper offers some directions to a behavior-analytic approach of what has been referred to as emotional self-control. According to Behavior Analysis, no new process is found in emotional self-control, but components that are additional to those found in behavioral self-control, which require appropriate treatment. The paper highlights some determinants of behavioral repertoires taken as instances of emotional self-control: the social context in which self-control is produced and maintained; the conflicts between consequences for the individual and for the group; and the degree of participation of the motor apparatus in the emission of emotional responses.

Keywords: emotional self-control; emotional responses; inner world; behavior analysis.

Uma proposição da filosofia behaviorista radical, que fundamenta a Análise do Comportamento, diz respeito à interpretação de emoções como fenômenos comportamentais, contrariando uma separação entre comportamento e emoção historicamente assumida pela Psicologia. Sob essa perspectiva, quando a Análise do Comportamento discute o autocontrole (e.g., Marchezini-Cunha, 2004; Nico, 2001; Rachlin, 1974; Skinner, 1958/1998), ela o faz enquanto relações comportamentais. Uma eventual distinção entre autocontrole emocional e autocontrole comportamental, tal como sugerida em análises cognitivistas (e.g., Wills,
Walker, Mendoza e Ainette, 2006) não tem sido objeto de considerações nos textos de Análise do Comportamento sobre o autocontrole, seja para admiti-la como relevante, seja para contestar sua pertinência. No presente artigo, apresenta-se aquela distinção, sob o enfoque cognitivista, e oferecem-se algumas direções para uma interpretação analítico-comportamental do chamado autocontrole emocional, evitando-se a atribuição de um status não comportamental à emoção.

A abordagem do autocontrole comportamental e do autocontrole emocional como dois processos distintos pode ser ilustrada com a análise de Wills, Walker,

* Endereço para correspondência: Jussara Rocha Batista - ju_rbatista@yahoo.com.br

** Endereço para correspondência: Emmanuel Zagury Tourinho - eztourinho@gmail.com 
Mendoza e Ainette (2006). Ao abordarem o autocontrole emocional, Wills et al. sugerem que "a construção da regulação emocional enfatiza lidar com ansiedade, depressão e raiva." (p. 266). Referindo-se ao que corresponderia ao autocontrole comportamental, os autores afirmam:

Em artigos teóricos típicos, o autocontrole é definido como um grupo de habilidades relacionadas que envolvem aspectos tais como focar e mudar a atenção, comportamento de monitoramento, relacionar comportamentos e consequências ao longo do tempo, e considerar alternativas antes de agir. (p. 265)

Resumidamente, portanto, para Wills et al. (2006), o autocontrole emocional estaria relacionado ao controle de emoções tidas como negativas (ansiedade, depressão e raiva), enquanto o autocontrole comportamental estaria relacionado a padrões comportamentais de planejamento, resolução de problemas, esforço cognitivo e autorreforçamento.

$\mathrm{Na}$ literatura cognitivista sobre autocontrole, o autocontrole emocional é considerado uma característica individual, geralmente positiva nas relações sociais ou em processos terapêuticos (Bryan, 2007; Bryan, Lisa \& Gladys, 2005; Christensen, Benotsch, Wieb \& Lawton, 1995; Evangelos \& Panagiotis, 2003; Kraag, Zeegers, Koc, Hosman \& Abu-Saad, 2006; Medlar, 1998), visto que resulta na baixa emissão de respostas emocionais negativas, favorecendo interações sociais proveitosas para o indivíduo. Muitos desses estudos concordam com o fato de que cada indivíduo pode apresentar níveis diferentes de autocontrole de suas próprias emoções. $\mathrm{O}$ autocontrole emocional costuma, inclusive, compor escalas para medir, por exemplo, a inteligência emocional (Bryan, 2007).

Para cognitivistas e behavioristas, pode fazer sentido falar em autocontrole emocional referindo a redução na emissão de respostas emocionais "negativas" (que têm função aversiva para o outro), mas para os primeiros essa redução pode ser função de ocorrências internas, como a "força de vontade", que levarim o indivíduo a controlar seu próprio comportamento. Há também circunstâncias em que a abordagem cognitivista significa que um evento emocional (não comportamental) foi o alvo do controle. Uma definição de autocontrole de um dicionário de língua portuguesa ilustra essa segunda possibilidade: autocontrole é o "controle de si mesmo; domínio de seus próprios impulsos, emoções e paixões" (Encyclopaedia Britannica do Brasil, 1990, p. 225).
$\mathrm{Na}$ Análise do Comportamento, tem-se uma única interpretação para o autocontrole, que pretende dar conta tanto do que os cognitivistas denominam autocontrole comportamental, quanto do que designam autocontrole emocional. Apesar disso, deve-se reconhecer que raramente as emoções são referidas nos textos analítico-comportamentais sobre o autocontrole, daí a necessidade de exame do problema, começando-se com as definições oferecidas por Skinner para o autocontrole.

De acordo com Skinner (1953/1998), um indivíduo controla o seu próprio comportamento da mesma maneira como controla o comportamento de outro. Para isso, ele manipula variáveis de forma a tornar provável a emissão de uma resposta antes pouco provável. Para o autor, a emissão de uma resposta autocontrolada sempre envolve conflito de consequências, geralmente consequências reforçadoras e punidoras da resposta a ser controlada pelo indivíduo. Por exemplo, quando o indivíduo obedece a um sinal de trânsito e para na faixa de pedestres, está agindo de modo autocontrolado, no sentido de que está evitando a punição contingente ao avanço sobre a faixa, em vez de responder sob controle de outro evento que pode ser reforçador, como chegar mais rapidamente ao destino.

Além do conflito entre consequências, o lócus temporal é considerado um aspecto importante para analisar o autocontrole (Rachlin, 1974; Rachlin, 2000) e tem sido explorado por analistas do comportamento em estudos experimentais (e.g. Ito \& Nakamura, 1998) e aplicados (e.g., Binder, Dixon \& Ghezzi, 2000). Do ponto de vista temporal o conflito encontrado no autocontrole compreende consequências imediatas e atrasadas. Nesse caso, autocontrole ou impulsividade constituem cursos de ação possíveis e concorrentes, implicando, cada um, consequências positivas e aversivas. $\mathrm{O}$ padrão autocontrolado de respostas é aquele sob controle de uma condição reforçadora atrasada de maior magnitude (mesmo que acompanhada da perda de um reforçador imediato de menor magnitude). A impulsividade seria caracterizada pelo responder sob controle de uma consequência reforçadora imediata de menor magnitude, geralmente acompanhada de uma consequência atrasada aversiva. Voltando ao exemplo do motorista, a resposta (de não respeitar a faixa) é impulsiva se emitida sob controle da chegada mais rápida ao destino, mesmo que isso também venha acompanhado de uma multa e/ou sanções sociais; parar na faixa corresponde ao responder autocontrolado quando implica evitar a multa (consequência atrasada), mesmo que perdendo o reforçador imediato (chegar mais ra- 
pidamente ao destino). Como se vê, o contexto de conflito e temporalidade de consequências é essencial para falar-se de autocontrole e impulsividade.

De acordo com Rachilin (1974), embora o autocontrole envolva uma situação de escolha, só falamos de autocontrole quando se trata de manipular o ambiente para favorecer a escolha que, sem tal manipulação, teria uma probabilidade menor de ocorrer (exatamente porque a consequência reforçadora é mais atrasada). Por exemplo, falamos de autocontrole quando um indivíduo fecha as janelas do seu quarto para eliminar ruídos de uma festa e aumentar a probabilidade de estudar, mas não falamos de autocontrole quando o indivíduo guarda os livros no armário e, com isso, aumenta a probabilidade de sair para a festa.

Para a Análise do Comportamento, emoções são relações comportamentais e, como tal, compreendem eventos com função de estímulo e com função de resposta. Duas características usualmente distinguem tais fenômenos: primeiro, envolvem uma interação entre relações respondentes e operantes; segundo, compreendem respostas que são emitidas de forma encoberta. Nas relações que participam da emoção, uma resposta proeminente (para usar uma expressão de Kantor \& Smith, 1975, discutida adiante) é frequentemente fisiológica (por exemplo, ruborizar), mas geralmente o fenômeno emocional total também envolve respostas motoras (por exemplo, agir em direção a fontes de reforçamento, ou fugir de eventos punidores, geralmente sob controle parcial do evento fisiológico). Basicamente, falamos de autocontrole emocional quando o comportamento alvo do autocontrole inclui essa interação de relações respondentes e operantes.

Nas sessões seguintes, discute-se mais detalhadamente o autocontrole emocional sob a ótica da análise do comportamento. Pretende-se destacar inicialmente o contexto cultural em que se estabeleceu a concepção tradicional de autocontrole de emoções, enquanto processos e eventos internos ao indivíduo. Em seguida, busca-se mostrar como a Análise do Comportamento interpreta os fenômenos emocionais e o que distingue comportamentos ou respostas emocionais. Com isso, este trabalho buscará contrapor uma interpretação analítico-comportamental às definições tradicionais de autocontrole, compreendidas predominantemente como controle de impulsos e emoções.

\section{Aspectos sócio-históricos do autocontrole}

As formas tradicionais de definir autocontrole, que fazem referência a motivações internas ou à força de vontade do indivíduo, podem ser compreendidas como produto de um contexto de modificações históricas em relações sociais e econômicas.

De acordo com Elias (1987/1994), no final da Idade Média e início da Idade Moderna, modificações na ordem econômica na Europa ocidental foram seguidas também por modificações no âmbito das relações sociais. A mudança de uma economia de subsistência para uma economia de mercado propiciou um crescente processo de individualização. Este processo envolveria um afastamento no padrão predominante de relações sociais. Enquanto nas sociedades feudais o sujeito estava preso à sua condição de origem e fenômenos como sentimentos e emoções eram experimentados predominantemente no plano das relações com os outros, nas sociedades de mercado o indivíduo não estará mais preso à sua condição de origem e sentimentos e emoções passaram a ser experimentados predominantemente de forma privada e como ocorrências internas. A própria separação entre mundo público e mundo privado emerge nesse processo de transformação social (Tourinho, 2009).

Segundo Elias (1987/1994), a formação de uma economia de mercado aumentou a variedade de funções sociais e multiplicou os possíveis cursos de ação dos indivíduos. O comportamento de escolha tornou-se muito mais demandado na vida cotidiana, ao mesmo tempo em que os indivíduos deixaram de contar regularmente com o apoio de outros membros da sociedade em suas escolhas. Com a dissociação dos interesses coletivos e individuais e cada indivíduo indo em busca de suas realizações pessoais, o "outro" passou a representar em muitos contextos um obstáculo ao sucesso pessoal. Um resultado desse processo de mudanças foi que os indivíduos de uma sociedade de mercado passaram a evitar demonstrar publicamente o que sentem ou pensam. A não publicização de sentimentos e emoções tornou-se diretamente relacionada às chances de sucesso pessoal.

Outro aspecto discutido por Elias (1987/1994) diz respeito ao fato de que, com várias pessoas indo em busca de suas realizações pessoais individualmente, a regulação das relações interpessoais pelo Estado avançou fortemente, ao mesmo tempo em que fazer essa regulação intervindo diretamente no comportamento de cada indivíduo configurou-se como uma tarefa inalcançável. A solução foi promover também uma espécie de autorregulação, em que cada indivíduo age na direção de monitorar e controlar seu próprio comportamento. Isto é, nas sociedades de mercado, as exigências de autorregulação impostas pelos conflitos 
de interesse na vida cotidiana, associadas ao fato de que o sucesso depende da omissão aos outros dos próprios sentimentos e emoções, tornaram cada vez mais necessário o autocontrole. Neste contexto, o acesso às funções da vida adulta (cada vez mais diferenciadas das funções de não adultos) tornou-se crescentemente dependente da aquisição de repertórios refinados de autocontrole.

Ariés (1981) enfatiza que a noção de infância presente nos dias atuais foi construída ao longo dos últimos séculos. A infância nas sociedades feudais não era vista como uma fase especial da vida. As crianças não se encontravam afastadas do mundo adulto; ao contrário, participavam dos jogos, festas, aprendendo ainda profissões na prática, sob supervisão de adultos. No entanto, as modificações socioculturais ocorridas na transição para a Idade Moderna levaram a um afastamento da criança do mundo adulto e cada vez mais foi exigido que ela agisse de modos ditos civilizados. Por essa razão foram criadas as escolas e cada vez mais os códigos de civilidade foram tomando o lugar da contenção física (um tipo de ação direta para evitar a agressão ao outro) como forma de conter modos de agir impulsivamente. $\mathrm{O}$ autocontrole passou a ser ensinado desde muito cedo, mostrando-se muito mais vantajoso para regular as ações das crianças. Como Elias (1987/1994) coloca:

Justamente por ser tão vasta a discrepância entre a atitude das crianças e a que se exige dos adultos, o jovem já não é colocado, quando criança, no degrau mais inferior da carreira funcional que está destinado a escalar, como nas sociedades mais simples. Não aprende diretamente, servindo a um mestre adulto de sua futura função, como fazia um pajem de um cavaleiro ou um aprendiz de um mestre artesão. Ele é inicialmente afastado da esfera dos adultos por um período longo que ainda continua a crescer. Os jovens que se preparam para uma gama cada vez mais variada de funções já não são diretamente treinados para a vida adulta, mas o são indiretamente, em institutos, escolas e universidades especializados. (p. $33)$.

Sobre isto, Tourinho (2006a) coloca que o padrão civilizado de comportar-se socialmente pode ser analisado segundo o grau de autocontrole requerido. Nas sociedades ocidentais modernas, os indivíduos são levados a todo momento a auto-observar seu próprio corpo e comportar-se socialmente de modo eficiente significa pensar antes de agir, verificar possíveis consequências de seus comportamentos sociais.
Segundo Tourinho (2006a), as exigências de autocontrole que foram progressivamente impostas às sociedade ocidentais modernas levaram os indivíduos a experimentar sentimentos, emoções e cognições como ocorrências do ou no indivíduo. Para Elias (1987/ 1994), controlar os impulsos emocionais significava não deixar que atingissem o aparelho motor, de modo que com isso se evitava que o outro tomasse conhecimento dos sentimentos, pensamentos, emoções (ou, mais propriamente, da probabilidade de o indivíduo agir de um ou outro modo). Essa constante exigência de auto-observação e autocontrole levou os indivíduos a uma experiência desses fenômenos como privados e internos.

Elias (1987/1994) utiliza a noção de homo clausus para se referir ao homem que experimenta sentimentos, emoções e cognições como eventos internos. Esse modo de experimentar emoções dá origem a uma autopercepção como se o homem estivesse enclausurado dentro de si mesmo e a pele fosse uma fronteira que separaria o indivíduo da sociedade. Ao lado disso, quanto maiores as chances de escolha em uma sociedade, mais os indivíduos se veem como autônomos e livres para realizar escolhas, embora suas ações estejam a todo momento sendo reguladas socialmente por redes de interdependência pouco perceptíveis e fenômenos que são considerados particularidades individuais se constituam no plano das relações sociais.

As proposições de Elias ajudam a compreender por que sentimentos, emoções, pensamentos e cognições passaram a ser experimentados como fenômenos internos, e compreender ainda que aquilo que está contido dentro do indivíduo não são seus impulsos ou sua "real natureza humana". Segundo Tourinho (2006a), o que é referido como um processo de contenção de impulsos pode igualmente ser descrito como o aprendizado de um padrão de comportamento social em que não estão presentes certos componentes motores das respostas emocionais (em geral, incondicionadas).

A proposição de Elias (1987/1994) de que sentimentos e emoções não deixam de ser fenômenos relacionais, em que pese serem experimentados pelo indivíduo como ocorrências internas suas, está de acordo com a visão de uma ciência do comportamento, que enfoca os fenômenos afetivos como relações comportamentais.

Partindo do pressuposto de que nenhuma parcela do ambiente se constitui como um estímulo a menos que se torne diferenciada para o organismo, ocorrências no próprio corpo só passam a ser estímulos para respostas autodescritivas, como sentimentos e emo- 
ções, após a comunidade verbal ensinar a diferenciar essas ocorrências. Dessa maneira, é a própria comunidade verbal que modela e mantém essas respostas (Skinner, 1945). Segundo Andery (1999), "é através da comunidade verbal que se constrói uma parte importante do repertório dos seres humanos: sua subjetividade.” (p. 205) É precisamente através da relação com os outros que o sujeito responde diferencialmente a ocorrências de seu próprio organismo. Antes, porém, de definir e analisar o autocontrole de emoções dentro de uma perspectiva analítico-comportamental, cabe rever a noção de resposta emocional, examinar o que a diferencia de outros tipos de resposta, e como ela pode ser compreendida dentro da classe mais abrangente de fenômenos emocionais.

\section{Uma Breve Definição de Resposta Emocional}

$\mathrm{Na}$ análise do comportamento, é frequente o uso do termo eventos privados para referir-se aos fenômenos emocionais, assim como a fenômenos cognitivos, como pensamento, lembrança etc. Nas duas situações o conceito de eventos privados destaca a inacessibilidade à observação pública direta de certos estímulos ou respostas. Assim, uma característica de fenômenos comportamentais emocionais é que deles participam eventos (estímulos ou respostas) inacessíveis à observação pública (embora se possa falar em níveis diferentes de observabilidade).

Tourinho (2006b) aponta que há diferentes razões para que estímulos e respostas sejam inacessíveis à observação pública. Uma resposta não é encoberta ou privada por existir uma barreira física entre observador e observado, mas sim como resultado de aspectos formais e relacionais da resposta. Tourinho (2006a) parte da proposição de Kantor e Smith (1975), de que uma resposta é emitida pelo organismo como um todo e de que os graus de observabilidade dependerão do grau de ativação do aparelho motor na emissão da resposta. Tourinho (2006a) então sugere que as respostas possuem diferentes graus de observabilidade, pois dentre os sistemas orgânicos que participam da emissão de uma resposta alguns podem, a cada momento, ser mais proeminentes do que outros. Isso é especialmente relevante quando consideramos a participação dos sistemas que integram o aparelho motor, cujo grau de ativação por ocasião da emissão de uma resposta em grande medida define a acessibilidade dos outros à resposta. A observabilidade também dependerá do grau de familiaridade entre observador e observado, do treino que o observador possui para discriminar esses eventos e da utilização de instrumentos que auxiliam o observador na discriminação desses eventos.

Segundo Tourinho (2006b, 2009) quando analistas do comportamento falam de eventos privados, podem estar sob controle de três classes de eventos/fenômenos: condições anátomo-fisiológicas, estímulos e respostas como componentes de relações comportamentais, e relações comportamentais. Os conceitos emocionais, igualmente, costumam ser usados sob controle de eventos/fenômenos do mesmo tipo. Por exemplo, o conceito de medo pode ser usado sob controle de uma alteração fisiológica como a palidez, de uma resposta de esquiva, ou de padrões complexos de interação com uma dada situação (incluindo respostas verbais do tipo "estou com medo").

As várias instâncias de um fenômeno descrito como uma emoção particular podem ser analisadas com base nos níveis de determinação considerados pelos analistas do comportamento (fillogênese, ontogênese e cultura). Tourinho (2006b) propõe analisar essas instâncias considerando as relações que as compõem, segundo um modelo de análise da complexidade dos fenômenos comportamentais. Um fenômeno emocional seria mais ou menos complexo dependendo dos níveis de seleção por consequência que deram origem às relações que o compõem. De acordo com Tourinho (2006b):

A complexidade dos fenômenos comportamentais humanos relacionados à privacidade pode ser tratada como função de processos seletivos repetidos, envolvendo a participação de variáveis filogenéticas, ontogenéticas e culturais. Eu proponho que um continuum de complexidade pode ser derivado dessa perspectiva. Em uma extremidade desse continuиm, os fenômenos comportamentais estariam limitados a relações filogenéticas, o que inclui respostas sob o controle de eventos que adquiriram função de estímulo na história filogenética do homem. É claro que esse é um zero ideal do continuиm, uma vez que nenhuma relação real pode ser interpretada como resultante apenas da filogênese. (pp. 24-25)

Skinner (1953/1998) destaca que quando um indivíduo diz sentir uma determinada emoção ele está se referindo a respostas dos músculos e glândulas, como o corar ou o chorar (um exemplo de menor complexidade). Para Skinner (1974), nós respondemos ao nosso próprio corpo através de três "sistemas nervosos": o interoceptivo, que envolveria estimulações viscerais e glandulares; o proprioceptivo, que envolveria estimulações de músculos, juntas e tendões; e o extero- 
ceptivo, que envolveria estimulações sensoriais visuais, táteis, olfativas, gustativas e auditivas. Os sistemas proprioceptivo e interoceptivo envolveriam o tipo de estimulação relacionado ao sentir.

No entanto, para Skinner (1974), o que ocorre dentro do indivíduo só se torna diferenciado quando a comunidade verbal o leva a observar e a descrever suas ocorrências "internas". Essas respostas de auto-observação e autodescrição geralmente participam dos fenômenos emocionais de um indivíduo adulto em nossa cultura.

Em várias ocasiões Skinner (1953/1998) examina fenômenos mais complexos e argumenta que respostas emocionais são muito mais do que estimulações de glândulas e músculos, mas também predisposições para agir de determinados modos. Skinner (1953/ 1998) utiliza ainda a noção de emoção total para afirmar que uma emoção pode compreender relações operantes e respondentes. Skinner (1953/1998) exemplifica:

Ao descrever o fato de que críticas ao seu trabalho "enfurecem o empregado", podemos dizer, por exemplo: (1) que ele fica vermelho, que as palmas de suas mãos transpiram, e, se os dados forem observáveis, que pára de comer o almoço; (2) que sua face assume uma expressão característica de raiva; e (3) que tende a bater portas, a maltratar o gato, a falar secamente com os companheiros de trabalho, a brigar, e a assistir brigas de rua ou lutas de boxe com interesse especial. (p. 182)

A emoção total é compreendida por Skinner como o efeito total das críticas ao trabalho. Sendo assim, é possível afirmar que a emoção total está relacionada a todas as respostas emocionais (respondentes e operantes) do indivíduo. Eventos que participam das relações respondentes (por exemplo, uma resposta fisiológica de taquicardia) podem, nesse contexto, adquirir funções também em relações operantes (por exemplo, de estímulo discriminativo para a fuga).

Sobre esta questão, Darwich (2007) afirma, em acordo com o enfoque skinneriano, que os fenômenos emocionais são constituídos não só por componentes respondentes, como também componentes operantes. Para isso, utiliza um modelo de análise de acordo com o qual uma contingência operante produz uma relação respondente. Após a ocorrência de uma relação operante, as consequências reforçadoras podem eliciar respostas emocionais que, por sua vez, adquirem função de estímulos discriminativos para a resposta operante. Darwich e Tourinho (2005) ilustram essa análise:
Diante de uma moça, em uma festa (EA [estímulo antecedente]), um rapaz pergunta se ela gostaria de dançar (R1 [resposta operante]) e ela aceita o convite (EC) [evento consequente à resposta operante]). Considerando que o evento consequente (EC) apresenta a função de estímulo reforçador (SR) para o rapaz, a relação R1-SR propicia a ocorrência de seleção comportamental e a aquisição de função discriminativa por eventos semelhantes a EA (SD1 [estímulo discriminativo presente no ambiente externo]). Na medida em que EC também apresente função eliciadora (SE1 [estímulo eliciador incondicionado ou condicionado]), ele evoca respostas fisiológicas correspondentes a alterações nas condições corporais do indivíduo (R2 [resposta fisiológica, respondente]). A mesma relação respondente (SE1R2) pode, então, ficar condicionada à presença de EA (função de SE2 [estímulo eliciador condicionado]). Em situação futura semelhante a EA, as alterações nas condições corporais (R2), evocadas por SE2 (identificadas verbalmente como motivação para convidar uma moça par a dançar, por exemplo), também adquirem função discriminativa (SD2 [estímulo discriminativo presente no ambiente interno]) para a emissão de R1. (p. 115)

Fenômenos emocionais, portanto, são fenômenos comportamentais que compreendem uma interação entre relações respondentes e operantes, e das quais participam estímulos e/ou respostas encobertas. São produtos de seleção em vários níveis e com graus variados de complexidade. As respostas envolvidas nessas relações vão de respostas com participação mais proeminente de componentes glandulares a respostas com participação mais proeminente de componentes motores. No último caso, porém, variáveis culturais podem fazer com que os componentes motores sejam mais discretos, ou mesmo que sejam opostos aos componentes motores de um padrão produzido apenas por outros níveis de determinação. Isso é o que ocorre, por exemplo, quando um indivíduo é confrontado com alguém que o ameaça (como um assaltante armado) e, no lugar de agredi-lo, tenta conversar.

\section{O Autocontrole Emocional: Interpretações Cognitivistas Criticadas pela Análise do Comportamento}

$\mathrm{Na}$ linguagem coloquial, prevalece o uso do conceito de autocontrole em referência a impulsos, instintos e paixões tidos como ocorrências internas, eventualmente contidas por uma faculdade do próprio indivíduo, como sua razão ou seu intelecto. Rachlin (2000) trata dessa concepção internalista considerando 
três visões populares da "força de vontade": uma religiosa, outra cartesiana e outra das neurociências cognitivas modernas.

À luz de uma perspectiva religiosa, herdada de Santo Agostinho, a força de vontade, que levaria o indivíduo a exercer controle sobre suas próprias ações, envolve a luta entre as forças do bem e do mal. O indivíduo deve ter força de vontade para resistir às tentações. Para isso, é dotado de livre arbítrio, podendo escolher entre as boas influências externas, da igreja, e as más influências internas, das tentações. "O resultado final do autocontrole de um ponto de vista religioso é um corpo sob o melhor controle do ser" (Rachlin, 2000, p. 13).

Segundo Rachlin (2000), no modelo cartesiano, o comportamento de homens e animais obedece a leis mecânicas. No comportamento reflexo, estímulos externos atingiriam os órgãos dos sentidos e abririam uma válvula dentro do organismo que transmitiria os fluidos animais aos músculos e nervos, produzindo assim o comportamento reflexo. Porém, o comportamento dos seres humanos também é controlado por estímulos internos. Para Descartes, a alma ou a razão seria a fonte principal de controle do comportamento. Assim, estímulos externos atingiriam os órgãos dos sentidos e estímulos internos, provenientes do próprio ser, abririam a válvula que levaria os fluídos animais até os músculos e nervos. Estes dois caminhos seriam responsáveis pelo controle do comportamento: um controle externo, responsável por comportamentos reflexos, e outro de autocontrole.

Ainda de acordo com Rachlin (2000), nas abordagens cognitivo-comportamentais os comportamentos são função de informações processadas na mente, ou no cérebro, do mesmo modo que informações são processadas em um computador. Nesses casos, há uma entrada de informações (input), o processamento interno destas e o comportamento produzido (output). Sendo assim, a explicação para o comportamento deve ser buscada dentro do organismo, em processos cognitivos inferidos, não em variáveis externas.

Rachlin (2000) argumenta que o autocontrole, do ponto de vista da neurociência cognitiva moderna, permanece analisado enquanto um processo interno. As informações entrariam no sistema cognitivo, localizado no cérebro superior, e combinadas com a memória "declarativa" formariam ideias sobre o mundo, que retornam ao cérebro inferior, no qual emoções estão sendo processadas e formam proposições. As proposições fazem um caminho de volta, e estímulos entram no cérebro inferior e resultam no comportamento. Nesta perspectiva, mecanismos abstratos são reificados e são vistos como o que determina o autocontrole pelo indivíduo.

Uma evidência de que concepções tradicionais do autocontrole continuam com grande aceitação é o fato de o autocontrole emocional ser encontrado na literatura atual como subescala na mensuração da inteligência emocional (Rego e Fernandes, 2005; Mogavero, 2000). Tem-se, aqui, a ideia de que se autocontrolar depende das capacidades do próprio indivíduo, de sua força de vontade para resistir a tentações, ou como foi colocado anteriormente, para agir de modos civilizados.

Alguns estudos avaliam o autocontrole emocional por meio de uma escala, cujo objetivo é medir a manutenção de valores culturais de populações asiáticas que moram nos Estados Unidos. Bryan (2007) e Bryan et al. (2005) sugerem que a manutenção de valores culturais asiáticos poderia auxiliar em tratamentos psicológicos dirigidos a essa população. A escala referida apresenta itens como "é melhor expressar emoções do que sofrer em silêncio" e "é mais importante se comportar adequadamente do que agir de acordo com o que se está sentindo" (Bryan et al., 2005, p. 192), cada item com 7 níveis de medida. No estudo de Bryan et al. (2005), os resultados mostraram o autocontrole emocional como variável relacionada à baixa procura por atendimento psicológico, porém, no estudo de Bryan (2007), não houve confirmação desses resultados.

Nesses estudos, a noção de controle de emoções remete a diferenças culturais. Desse ponto de vista, aproximam-se da perspectiva relacional da análise do comportamento, pois para a última as formas de emissão de respostas emocionais difeririam de uma cultura para outra, dependendo do grau de autocontrole exigido socialmente. No entanto, há aspectos que ainda remetem a uma noção internalista do autocontrole de emoções como "é melhor conter as próprias emoções internamente do que incomodar os outros expressando-as" (Bryan et al., 2005, p. 192).

Outros estudos no campo da psicologia, embora não definam autocontrole emocional, o colocam como uma qualidade individual útil em várias esferas de atuação humana. O estudo de Christensen et al. (1995), por exemplo, sugere que o autocontrole emocional seria uma das variáveis que auxiliariam na adesão ao tratamento por pacientes que realizam tratamento de hemodiálise. O estudo de Evangelos e Panagiotis (2003) sugere que atletas mais velhos que foram mais bem 
preparados para resistir ao stress psicológico envolvido na prática de badminton mostraram melhor autocontrole emocional. Assim, o autocontrole emocional poderia ser desenvolvido por técnicas de redução de stress. $\mathrm{O}$ autocontrole emocional foi ainda relacionado ao bom desenvolvimento de inibição sexual por pessoas com lesão cerebral (Medlar, 1998), e o pobre autocontrole emocional foi diretamente relacionado ao uso de drogas por adolescentes (Wills et al., 2006).

Os estudos citados acima demonstram a importância do autocontrole, neste caso autocontrole emocional, em diversas esferas de atuação humana, principalmente de consequências importantes para o grupo social, como a diminuição de comportamentos agressivos, diminuição do uso de drogas, resolução de problemas de saúde pública etc. Neste sentido, também sinalizam o fato de que o autocontrole seria aprendido e mantido socialmente, estando a fonte de controle final no ambiente. A Análise do Comportamento pode oferecer uma elaboração nessa direção, sem a necessidade de recorrer-se a processos internos.

\section{Autocontrole Emocional: Contrapontos da Análise do Comportamento}

Partindo de uma referência cognitivista, Wills et al. (2006) destacam que o autocontrole comportamental tem sido mais frequentemente analisado na literatura do que o autocontrole emocional, sendo o autocontrole comportamental relacionado à atenção, monitoramento do próprio comportamento e comportamento de escolha. Quanto ao autocontrole emocional, os autores o relacionam predominantemente à regulação de emoções negativas como raiva, medo e tristeza, instabilidade de estados de humor etc.

No estudo de Wills et al. (2006), foram utilizados vários tipos de escala para medir variáveis familiares, autocontrole comportamental e autocontrole emocional, bem como para correlacionar essas variáveis ao uso de drogas por adolescentes. Com relação ao autocontrole comportamental, os indicadores utilizados foram: capacidade de planejamento (planfulness), resolução de problemas, esforço cognitivo, autocontrole, distratibilidade e impulsividade. Os indicadores de autocontrole emocional foram: capacidade de se acalmar (soothability), controle da tristeza, controle da raiva, supressão da tristeza, supressão da raiva, ruminação da tristeza, ruminação da raiva, reação de raiva, instabilidade afetiva negativa, instabilidade afetiva positiva.
Um aspecto interessante é que alguns dos indicadores utilizados no estudo de Wills et al. (2006) foram compostos por itens que faziam menção a diferentes níveis de emissão da resposta emocional, podendo se inferir que o controle emocional se daria por não deixar que as respostas emocionais fossem acessíveis à observação pública. Por exemplo, os itens "eu tento esconder como eu me sinto" ou "eu escondo minha raiva". Estes itens sugerem que o autocontrole de emoções pode se dar quando a resposta é emitida com reduzida participação do aparelho motor. Esta perspectiva está em acordo com as propostas de Kantor e Smith (1975), de que todos os sistemas orgânicos participam da emissão de uma resposta, mas o que confere a observabilidade é a participação do aparelho motor. Esta noção está de acordo também com as colocações de Elias (1987/1994) para a definição de autocontrole, segundo as quais os indivíduos experimentam emoções como internas, quando há pouca participação do aparelho motor.

Outros itens estavam relacionados à emissão de respostas abertas (motoras) incompatíveis com respostas emocionais negativas (por exemplo, "quando eu me sinto pra baixo, eu posso controlar minha tristeza e continuar realizando outras coisas"). Nesse caso, temse um recurso sugerido com técnica de autocontrole na análise do comportamento, como se verá adiante.

Embora o controle de emoções não tenha sido tratado na Análise do Comportamento como uma forma de autocontrole distinta do autocontrole comportamental, alguns autores analisam o controle de emoções pelo próprio indivíduo, por meio da manipulação de condições ambientais que alteram a probabilidade de certas respostas (e.g., Marchezini-Cunha, 2004; Nico, 2001; Skinner, 1953/1998). Skinner (1953/1998), ao analisar a manipulação de variáveis que tornam a resposta autocontrolada mais provável, discute especialmente como a emissão de respostas emocionais pode ser controlada pelo próprio indivíduo. Considerando os componentes respondentes, essas respostas poderiam ser controladas alterando-se os estímulos que as eliciam. Isso, para Skinner, significa na maioria das vezes simplesmente apresentar ou suprimir estímulos que eliciam respostas emocionais. $\mathrm{O}$ indivíduo pode aumentar a probabilidade de emissão de respostas incompatíveis com respostas emocionais, pode retardar a reação emocional a fim de reduzir sua extensão, ou ainda modificar suas predisposições emocionais. Em todos os casos o objetivo do autocontrole é agir adequadamente ou de modos socialmente aceitáveis. Observe-se, porém, que tal manipulação tem relação 
também com os componentes operantes do fenômeno emocional, dada a interação entre respondentes e operantes na emoção e o fato de que os estímulos que participam das relações respondentes adquirem funções também em relações operantes e vice-versa. Por exemplo, considere-se a circunstância em que a presença de um agente punidor elicia respondentes associados ao "medo" (como alterações do batimento cardíaco) e exerce também uma função discriminativa para respostas de operantes de fuga (ocasião em que tanto as relações respondentes quanto as relações operantes seriam constitutivas da emoção de "medo" do agente punidor). A remoção do agente punidor altera a probabilidade da resposta reflexa e, também, a probabilidade das respostas operantes de fuga.

Sob o enfoque analítico-comportamental, o autocontrole requer autoconhecimento. Se o sujeito não conhece as variáveis das quais seu comportamento é função, não conseguirá manipulá-las. Por outro lado, conhecer as variáveis das quais o comportamento é função não é suficiente para que ocorra autocontrole, é necessário ainda que o ambiente social favoreça o autocontrole (por exemplo, dispondo consequências adicionais, como sanções éticas, ao comportamento impulsivo). Essa concepção de Skinner mostra mais uma vez a proximidade com as proposições de Elias (1987/1994), pois para este é a sociedade que exige constante auto-observação e autocontrole (o que leva os indivíduos a verem os fenômenos "subjetivos", sentimentos, emoções cognições, entre outros, como substâncias contidas dentro de si, que constituiriam sua natureza essencial).

A análise de Marchezini-Cunha (2004) para o autocontrole de emoções leva em consideração tanto as definições de Skinner para o autocontrole, quanto as definições de Rachlin. De acordo com Marchezini-Cunha (2004), a expressão adequada de emoções é denominada, na Psicologia, de assertividade e deve ser contrastada com dois padrões de expressão de sentimentos concorrentes, a agressividade e a passividade. Para a autora, a assertividade seria funcionalmente semelhante a padrões de comportamento autocontrolado e as respostas agressivas e passivas seriam funcionalmente semelhantes a padrões de comportamento impulsivo.

Desta maneira, tanto o que a Psicologia trata como assertividade quanto o que a Análise do Comportamento define como autocontrole implica consequências para o individuo e consequências para o grupo, que variam quanto ao tipo, à magnitude e ao atraso. Quando um indivíduo responde com uma declaração educada de desagrado a uma provocação desagradável de um amigo, produz consequências aversivas e positivas para si mesmo (em geral, moderadas) e consequências positivas para o grupo. Se fosse impulsivo e, por exemplo, rompesse a amizade, eliminaria mais prontamente a estimulação aversiva imediata, mas não produziria consequências positivas para si mesmo e produziria outras consequências aversivas atrasadas, para si mesmo e para o grupo. Esse seria um exemplo de resposta agressiva. Observe-se que, no caso da resposta autocontrolada, o componente operante é tal que concorre com o respondente e, desse modo, uma manipulação em variáveis que alteram sua probabilidade implica também o controle do componente respondente.

A passividade também é funcionalmente semelhante ao que é denominado resposta impulsiva, pois produz, em contextos de interação social, consequências sociais reforçadoras e consequências gerais aversivas para o indivíduo; e consequências reforçadoras a curto prazo, porém consequência aversivas a médio e longo prazos para o grupo.

Alguns aspectos do autocontrole emocional podem então ser destacados, de uma perspectiva analíticocomportamental: (1) trata-se de um padrão comportamental mantido por contingências sociais; (2) que envolve a interação entre relações respondentes e operantes, (3) em que a resposta no componente respondente é proeminentemente fisiológica e adquire função de estímulo para respostas operantes, que (4) em alguns casos são emitidas com reduzida participação do aparelho motor (ou com componentes motores concorrentes), daí sua fonte de inobservabilidade. $\mathrm{O}$ primeiro aspecto enfatiza que o autocontrole de emoções implica situações de interação social, quando há conflito de consequências para o indivíduo e para o grupo, como colocado por Marchezini-Cunha (2004). O segundo aspecto está relacionado ao fato de que as respostas fisiológicas são apenas cmponentes proeminentes de um sistema de reação/interação com o ambiente mais complexo. $\mathrm{O}$ terceiro aspecto remete ao fato de que tal complexidade decorre também das diferentes funções que os eventos (inclusive ocorrências do próprio corpo) adquirem na reatividade do organismo ao ambiente. Por último, o quarto aspecto salienta o que costuma induzir o leigo à atribuição de uma natureza especial ao autocontrole emocional, em que pese sua natureza comportamental.

$\mathrm{O}$ autocontrole emocional tem sido discutido principalmente sob a ótima de orientações teóricas cognitivistas, mas pode ser interpretado com os conceitos 
da Análise do Comportamento resultando em uma elaboração que o coloca no mesmo terreno (o das relações comportamentais) em que tem sido discutido o chamado autocontrole comportamental.

A referência a alguns determinantes sócio-históricos das práticas de autocontrole encontradas no mundo moderno e das concepções internalistas correspondentes é importante para situar o problema das várias modalidades de autocontrole no campo das práticas culturais e indicar os tipos de variáveis que precisam ser consideradas no curso da investigação do problema. Importa, por exemplo, considerar as situações de escolha, ou os esquemas concorrentes, que passam a ser frequentes na vida cotidiana, assim como as metas de longo prazo, ou a temporalidade das consequências contingentes a cada tipo de escolha etc..

Essa análise também sugere que uma distinção entre as modalidades de autocontrole referidas na literatura cognitivista pode ser relevante no sentido de chamar a atenção para o fato de que o fenômeno emocional compreende uma interação entre relações (respondentes e operantes) não identificadas necessariamente em todo fenômeno comportamental, mas para a Análise do Comportamento tal aspecto pode ser tratado sem a atribuição de um caráter não comportamental ao fenômeno emocional. O que a Análise do Comportamento tem discutido como autocontrole de fato correspondente mais precisamente ao que a literatura cognitivista tem tratado como autocontrole comportamental, mas pode compreender também o que tem sido descrito como autocontrole emocional, usando-se os mesmos princípios, os mesmos conceitos e a mesma lógica relacional. Para tal, é necessário integrar o que tem sido produzido sobre autocontrole, com o que tem sido avanços na abordagem da emoção sob o enfoque analítico-comportamental. Embora o autocontrole em situações que envolvem fenômenos emocionais tenha componentes adicionais aos encontrados no autocontrole em circunstâncias em que esses componentes estão ausentes, as diferenças são relativas propriamente à interação entre respondentes e operantes a à inacessibilidade à observação pública de (algumas) respostas envolvidas, fato que se relaciona a contingências sociais específicas.

Skinner (1968/2003) usa o conceito de autogerenciamento ético para caracterizar um tipo de autocontrole que envolve o conflito de consequências para o indivíduo e para o grupo. Um exame do que ocorre com respostas emocionais no autogerenciamento ético pode ser um ponto de partida para a discussão do autocontrole emocional na análise do comportamento.
As concepções sobre autocontrole de Elias (1987/ 1994) e de Skinner (1953/1998) assemelham-se em dois aspectos: (1) o controle final depende de contingências sociais e (2) a auto-observação é um pré-requisito necessário para que haja autocontrole. Um terceiro aspecto aproxima as concepções de Elias (1987/1994) às concepções da Análise do Comportamento, e mais claramente às concepções de Kantor e Smith (1975), relativas aos diferentes graus de observabilidade de uma resposta, como resultado de diferentes graus de participação aparelho motor na sua emissão.

Os vários estudos sobre autocontrole emocional têm o mérito de chamar a atenção para a importância do controle emocional em várias esferas da atividade humana. A sugestão nesses estudos de que pode haver vários níveis de autocontrole emocional está em acordo com as suposições da análise do comportamento de que o autocontrole é um padrão comportamental modelado e mantido por contingências sociais e de que os tipos e níveis de autocontrole dependem das exigências de civilidade ou contingências sociais presentes em cada sociedade. Quanto mais complexa a sociedade maior o nível de autocontrole exigido (Tourinho, 2006a).

\section{REFERÊNCIAS}

Andery, M. A. (1999). O modelo de seleção por consequências e a subjetividade. Em R. A. Banaco (Org.), Sobre comportamento e cognição: Vol. 1 (pp. 199-208). São Paulo: ABPMC/ARBytes.

Ariés, P. (1981). História social da criança e da família (D. Flaksman, Trad.). Rio de Janeiro: Zahar.

Binder, L. M., Dixon, M. R., \& Ghezzi, P. M. (2000). A procedure to teach self-control to children with attention deficit hyperactivity disorder. Journal of Applied Behavior Analysis, 33, 233237.

Bryan, S. K. K. (2007). Adherence to Asian and European American cultural values and attitudes toward seeking professional psychological help among Asian American college students. Journal of Couseinling Psychology, 54, 474-480.

Bryan, S. K. K., Lisa, C. L., \& Gladys, F. N. (2005). The Asian American Values Scale - Multidimensional: Development, reliability, and validity. Cultural Diversity and Ethnic Minority Psychology, 11, 187-201.

Christensen, A. J., Benotsch, E. G., Wiebe, J. S., \& Lawton, W. J. (1995). Coping with treatment-relatad stress: Effects on patients adherence hemodialysis. Journal of Consulting and Clinical Psychology, 63, 454-459.

Darwich, R. (2007). Fenômenos emocionais no contexto explicativo do modo causal de seleção por consequências (Tese de doutorado). Universidade Federal do Pará, Belém. 
Darwich, R. A., \& Tourinho, E. Z. (2005). Respostas emocionais à luz do modo causal de seleção por consequências. Revista Brasileira de Terapia Comportamental e Cognitiva, 7, 107-118.

Elias, N. (1994). A sociedade dos indivíduos (V. Ribeiro, Trans.). Rio de Janeiro: Jorge Zahar. (Trabalho original publicado em 1987)

Encyclopaedia Britannica do Brasil (1990). Dicionário brasileiro da língua portuguesa. São Paulo: Melhoramentos.

Evangelos, B., \& Panagiotis, A. (2003). Psychological skills of Greek badminton athletes. Percetual and Motor Skills, 97, 1289-1296.

Ito, M., \& Nakamura, K. (1998). Humans' choice in a self-control choice situation: Sensivity to reinforcer amount, reinforcer delay, and overall reinforcement density. Journal of the Experimental Analyses of Behavior, 69, 87-102.

Kantor, J. R., \& Smith, N. W. (1975). The reaction system. Em J. R. Kantor \& N. W. Smith (Eds.), The science of psychology: An interbehavioral survey (pp. 47-55). Chicago: Principia Press.

Kragg, G., Zeegers, M. P., Kok, G., Hosman, C., \& Abu-Saad, H. H. (2006). School program targeting stress management in children and adolescents: A meta-analysis. Journal of School Psychology, 44, 449-442.

Marchezini-Cunha, V. (2004). Assertividade e autocontrole: Possíveis relações (Dissertação de mestrado). Universidade Federal do Pará, Belém.

Medlar, T. (1998). The Sexuality Education Program of the Massachusetts Statewide Head Injury Program. Sexuality and Disability, 16, 11-19.

Mogavero, T. V. (2000). Client's perception of consultant's emotional intelligence as an indicator of client's perception of consultant's competence. Dissertation Abstracts International Section B: The Sciences and Engineering, 61, 1682. Resumo retirado da base de dados PsycINFO.
Nico, Y. C. (2001). A contribuição de B. F. Skinner para o ensino do autocontrole como objetivo da educação (Dissertação de mestrado). Pontifícia Universidade Católica de São Paulo.

Rachlin, H. (1974). Self-control. Behaviorism, 2, 94-107.

Rachlin, H. (2000). The science of self-control. Cambridge: Harvard University Press.

Rego, A., \& Fernandes, C. (2005). Inteligência emocional: Contributos adicionais para a validação de um instrumento de medida. Psicologia: Revista da Associação Portuguesa Psicologia, 19, 139-167. Resumo retirado da base de dados PsycINFO.

Skinner, B. F. (1945). The operational analysis of psychological terms. Psychological Review, 52, 270- 277.

Skinner, B. F. (1953/1998). Ciência e comportamento humano (J. C. Todorov e R. Azzi, Trans.). São Paulo: Martins Fontes.

Skinner, B. F. (1968/2003). The technology of teaching. Acton: Copley.

Skinner, B. F. (1974). About behaviorism. New York: Vintage Books.

Tourinho, E. Z. (2006a). Mundo interno e autocontrole. Revista Brasileira de Análise do Comportamento, 2, 21-36.

Tourinho, E. Z. (2006b). Private stimuli, covert responses and private events: Conceptual remarks. The Behavior Analyst, 29, 13-31.

Tourinho, E. Z. (2009). Subjetividade e relações comportamentais. São Paulo: Paradigma.

Wills, T. A., Walker, C., Mendoza, D., \& Ainette, M. G. (2006). Behavioral and emotional self-control: Relations to substance use in samples of middle and high school students. Psychology of Addictive Behaviors, 20, 265-278. 